\title{
Bull's Head Sign in a Patient with SAPHO Syndrome
}

\author{
Ufuk İlgen, Sezin Turan, Hakan Emmungil
}

Department of Rheumatology, Trakya University School of Medicine, Edirne, Turkey

A 53-year-old male was evaluated for upper chest pain lasting 3 years. The pain was continuous, bilateral, progressive, and worse when the patient lay on his sides and during hyperabduction of the arms, radiating to the shoulders. Initially, it was responsive to non-steroidal anti-inflammatory drugs, but full daily doses of combined long- and short-acting non-steroidal anti-inflammatory drugs had failed in the last few months, resulting in impairment of daily activities and disturbance of sleep, causing the patient to seek medical help. On physical examination, the sternoclavicular, manubriosternal, and upper two costosternal joints on both sides were tender. Systemic examination did not reveal any additional abnormal findings. He had no other symptoms. A complete blood count, basic biochemical tests, the erythrocyte sedimentation rate, and serum C-reactive protein were normal. Serum levels of calcium, phosphorus, alkaline phosphatase, and plasma parathormone and 25-hydroxy vitamin $\mathrm{D}_{3}$ were normal as well. A posteroanterior chest radiograph did not reveal any significant findings. Bone scintigraphy with ${ }^{99 \mathrm{~m}} \mathrm{Tc}-\mathrm{methylene}$ diphosphonate revealed increased osteoblastic activity in the manubriosternal, bilateral sternocostoclavicular, and lower cervical vertebral regions (Figure 1a). Computed tomographic examination of the anterior chest wall revealed hyperostosis and fusion of the first costosternal and manubriosternal joints (Figure 1b). ${ }^{18} \mathrm{~F}$-fluorodeoxyglucose positron emission tomography and computed tomography fusion images showed increased activity in the sternoclavicular joints (arthritis) and hyperostotic lesions (osteitis) (Figure 1c). Written informed consent was obtained from the patient regarding the use of clinical information and imaging findings for educational and research purposes.

A diagnosis of Synovitis, Acne, Pustulosis, Hyperostosis, Osteitis syndrome was made, and treatment with intravenous zoledronic acid resulted in complete relief of pain. Due to its rarity, diagnosis of Synovitis, Acne, Pustulosis, Hyperostosis, Osteitis syndrome may be challenging in the absence of the full clinical picture, especially cutaneous manifestations $(1,2)$. In this case, the diagnosis is guided mainly by typical radiological findings (3). Treatment options include non-steroidal anti-inflammatory drugs, corticosteroids, bisphosphonates, colchicine, and immunosuppressive or biological agents in refractory cases (1).
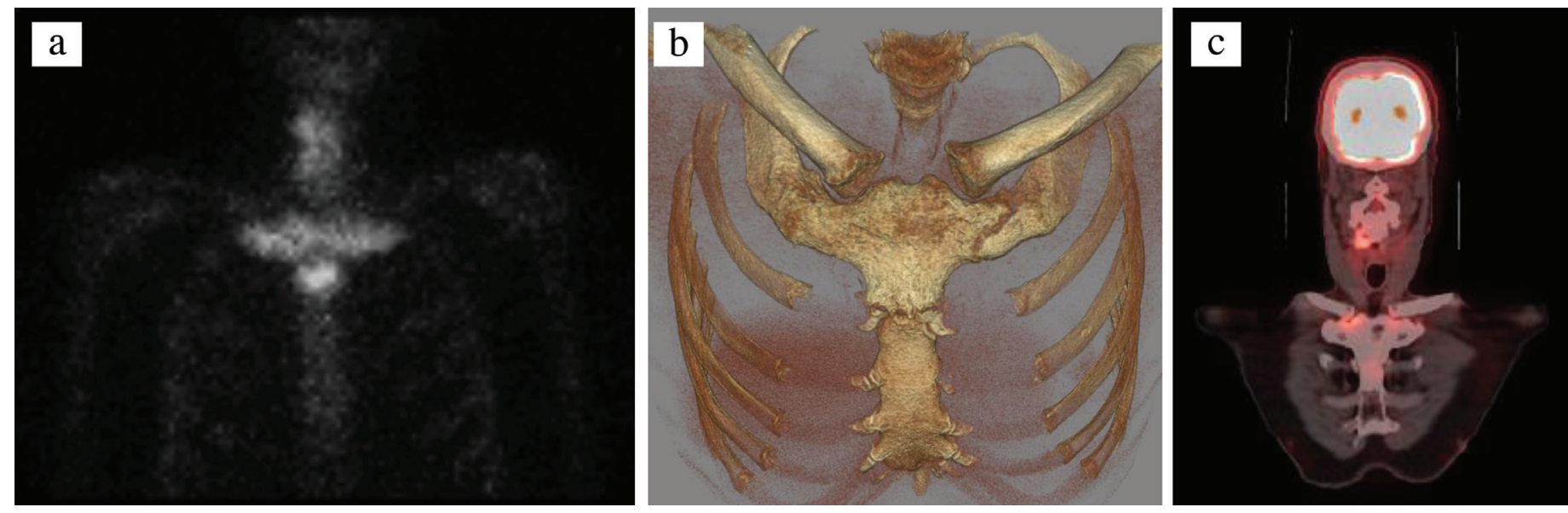

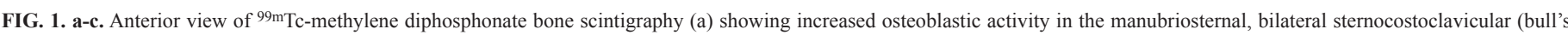

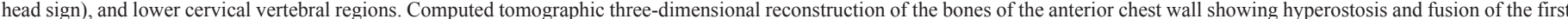

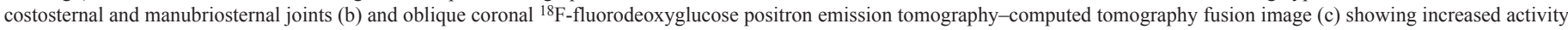
in sternoclavicular joints (arthritis) and hyperostotic lesions (osteitis).

Address for Correspondence: Ufuk İlgen, Department of Rheumatology, Trakya University School of Medicine, Edirne, Turkey

Phone: +905054461683 e-mail: ufukilgen@gmail.com ORCID: orcid.org/0000-0001-6443-6426

Received: 18 September 2018 Accepted: 19 November 2018 DOI: 10.4274/balkanmedj.galenos.2018.2018.1630

Available at www.balkanmedicaljournal.org

Cite this article as:

İlgen U, Turan S, Emmungil H. Bull's Head Sign in a Patient with SAPHO Syndrome. Balkan Med J 2019;36:139-40

Copyright 2019 by Trakya University Faculty of Medicine / The Balkan Medical Journal published by Galenos Publishing House. 
Editor-in-Chief's note: Hakan Emmungil is the member of the Editorial Board of Balkan Medical Journal. However, he did not take place at any stage on the editorial decision of the manuscript

Conflict of Interest: No conflict of interest was declared by the authors

\section{REFERENCES}

1. Cianci F, Zoli A, Gremese E, Ferraccioli G. Clinical heterogeneity of SAPHO syndrome: challenging diagnose and treatment. Clin Rheumatol 2017;36:2151-8.
2. Okuno H, Watanuki M, Kuwahara Y, Sekiguchi A, Mori Y, Hitachi S, et al. Clinical features and radiological findings of 67 patients with SAPHO syndrome. Mod Rheumatol 2018;28:703-8.

3. Duan N, Chen X, Liu Y, Wang J, Wang Z. Multimodal imaging findings of SAPHO syndrome with no skin lesions: A report of three cases and review of the literature. Exp Ther Med 2016;12:2665-70. 